\title{
A UTILIZAÇÃO DE MAPAS MENTAIS COMO FERRAMENTA DE ESTUDO E AVALIAÇÃO EM ENGENHARIA
}

DOI: 10.37702/2175-957X.COBENGE.2021.3481

Juliane Érika Cavalcante Bender - julianebender@cefetmg.br

CEFET MG

Avenida Corifeu de Azevedo Marques 5650

05340-002 - São Paulo - SP

Gerfenson Barbosa Ribeiro - gerfenson19@gmail.com

Imtraff Engenharia e Mobilidade

Rua Joaquim Murtinho 416

32185-270 - Contagem - MG

Resumo: : As metodologias ativas centralizam o discente no processo de aprendizagem, incentivando a criatividade e a autonomia, entre outras habilidades. Os mapas mentais podem ser entendidos como uma metodologia ativa por estimular o aluno a ser construtor do seu conhecimento ao organizar e relacionar mentalmente o conteúdo aprendido. Este trabalho aborda a utilização de mapas mentais como atividade de avaliação e presença em duas disciplinas distintas em um curso de engenharia durante o Ensino Remoto Emergencial. Foi realizada uma pesquisa sobre percepção dos discentes acerca da atividade realizada. Nesta, foi verificado que $71 \%$ dos alunos nunca tinham utilizado o mapa mental e que $31 \%$ dos estudantes encontraram dificuldades para criá-lo. Constatou-se ainda, por meio da pesquisa, o impacto positivo da atividade na assimilação do conteúdo ministrado. Ademais, $79 \%$ dos discentes demonstram a intenção de aplicar a ferramenta em outros momentos de estudo. Esses fatos demonstram a viabilidade e utilidade dos mapas mentais dentro de um contexto de aulas totalmente online, possibilitando a aprendizagem de forma ativa.

Palavras-chave: Educação. Aprendizagem ativa. Percepção do discente. Ensino superior. Ensino remoto. 


\section{(C) \\ 28 a 30 de SETEMBRO \\ A UTILIZAÇÃO DE MAPAS MENTAIS COMO FERRAMENTA DE ESTUDO E AVALIAÇÃO EM ENGENHARIA}

\section{INTRODUÇÃO}

Em janeiro de 2020, a Organização Mundial da Saúde (OMS, 2020a) apontou que o surto do novo coronavírus constituía uma Emergência de Saúde Pública de Importância Internacional (ESPII), o mais alto nível de alerta da Organização. Já em março de 2020, em razão da disseminação da doença em níveis mundiais, a OMS (2020b) passa a caracterizar a COVID-19 como uma pandemia. Dessa forma, o isolamento e distanciamento social, dentro das diversas medidas orientações para conter o avanço da doença, passa a ser recomendado (CONSELHO NACIONAL DE SAÚDE, 2020).

De acordo com Junior e Monteiro (2020), em razão das orientações de agências e conselhos de saúde, escolas públicas e privadas, de todos os níveis de educação, precisaram implantar o chamado Ensino Remoto Emergencial (ERE), com aulas e outras atividade educacionais em formato totalmente digital.

Moreira, Henriques e Barros (2020) comentam que docentes e discentes, em todo mundo, se viram obrigados a migrarem para o online, ao adaptarem sua metodologia de ensino para as novas plataformas. No caso da instituição de ensino onde foi realizada a atividade, as aulas síncronas eram ministradas pelo Microsoft Teams, gravadas e, posteriormente, disponibilizadas no ambiente virtual de aprendizagem determinado pela instituição ao instituir em caráter emergencial o ensino remoto. Analogamente, as aulas assíncronas também eram disponibilizadas na mesma plataforma.

Ao final de todas as aulas, tanto síncronas quanto assíncronas, eram disponibilizados exercícios como forma de avaliação e validação da presença do aluno no referido dia de aula. A atividade em apresentada neste estudo se encaixa nesse contexto.

Moreira, Henriques e Barros (2020, p. 352) defendem que mais que transpor e transferir as aulas para a forma virtual, deve-se incorporar "processos de desconstrução e que promovam ambientes de aprendizagem colaborativos e construtivistas nas plataformas escolhidas" - as chamadas metodologias ativas.

As metodologias ativas têm como preceito a utilização de técnicas e ações que possibilitem a autonomia dos discentes (MCGREW; SAUL; TEAGUE, 2000). Neste contexto de desafios - tanto para docentes quanto discentes - é apresentada a utilização de uma metodologia ativa, conhecida por mapa mental, como alternativa para incentivar a compreensão e assimilação do conteúdo transmitido aos discentes. A fim de entender a percepção dos estudantes que participaram da atividade, também foi realizada uma pesquisa de avaliação da atividade realizada.

\section{FUNDAMENTAÇÃO TEÓRICA}

\subsection{Aprendizagem ativa}

As metodologias ativas baseiam-se em formas de desenvolver o processo de aprender, utilizando experiências reais ou simuladas (CAMARGO; DAROS, 2018). Esta pode ser entendida como um compilado de ações, ou eventos, que integram o processo 
educacional, organizados a fim dos integrantes tenham motivação a processar, aplicar, interagir e dividir suas vivências e habilidades (BAEPLER et al., 2016).

Prince e Felder (2013) adicionam que a aprendizagem ativa são métodos instrucionais que integram os estudantes no processo de aprender, requerendo que estes realizem atividades relevantes e pensem sobre o que estão executando.

A aprendizagem ativa é centralizada no estudante, que é o responsável pela criação de seu conhecimento. É estimulada a autonomia do estudante para que este compreenda conceitos por si e relacione seu conhecimento prévio com as suas novas descobertas. Entende-se, assim, que o conhecimento que é construído pelo aluno, de forma ativa, seja mais significativo que uma informação transmitida de forma passiva (MCGREW, SAUL, TEAGUE, 2000; VILLAS-BOAS et al., 2011).

Villas-Boas et al. (2011) discorrem que se deve criar um ambiente de aprendizagem bem adaptado, possibilitando aos alunos o "aprender a aprender", e ao mesmo momento combinando diversos conhecimentos, capacidades e condutas desejadas para desenvolver as competências necessárias a um profissional da engenharia.

No contexto da pandemia de COVID-19, onde a realização da atividade e pesquisa se inserem, Dosea et al. (2020, p. 140) acreditam que "as lacunas entre a autonomia do aluno e a aprendizagem em modelos não presenciais, poderia ser suprimida ou amenizada, pelo uso de métodos ativos de aprendizagem (...)".

\subsection{Mapa mental}

O mapa mental é uma técnica de representar o conhecimento, organizando-o como uma rede ou outro diagrama não linear que incorpora elementos verbais e simbólicos. Estes são baseados na organização de informações por meio de hierarquias e categorias que fluem de uma imagem central em um fluxo livre, mas de forma organizada e coerente (BUDD, 2004; DHINDSA, MAKARIMI-KASIM, ANDERSON, 2011).

De acordo com Ferlin e Shmeil (2020), Tony Buzan desenvolveu esse método ao reparar que os discentes que utilizavam técnicas de anotação e estudo empregando cores, desenhos, ilustrações e símbolos eram aqueles que conseguiam melhores resultados de aprendizagem.

Ao combinar diferentes estímulos, como imagens, palavras, números, lógica, ritmo, cor e consciência espacial, na atividade (BUZAN; BUZAN, 2009), são utilizados os hemisférios direito e esquerdo do cérebro proporcionando melhor absorção do conteúdo ministrado ou estudado pelo discente (HERMANN; BOVO, 2006). Blokehead (2016) afirma que o mapa mental é cerca de $15 \%$ a $20 \%$ mais eficaz em ativar a memória e em desenvolver o aprendizado quando comparado aos métodos tradicionais de estudo.

É possível encontrar relatos de seu uso em diversas áreas do conhecimento. Por exemplo, Ferlin e Shmeil (2020) demonstram a aplicação dessa ferramenta com discentes do 1 을o perío de Engenharia de Produção de forma a despertar o entendimento geral sobre a temática "Engenharia". Dolival et al. (2017, p.1) apresentam a aplicação do mapa mental como estratégia para contribuir no "letramento matemático dos alunos com deficiência intelectual, dificuldades de aprendizagens e comportamentos desviantes", obtendo bons resultados ao empregar o método em sala de aula. Gabrich e Souza (2016), por outro lado, trazem o emprego deste como ferramenta de planejamento de aulas para o ensino jurídico. Por fim, Lopes e Richter (2014) demonstram a viabilidade da utilização dos mapas mentais no ensino da geografia, integrando o estudo sobre o espaço geográfico e a representação cartográfica. 


\section{ATIVIDADE DIDÁTICA PROPOSTA}

A atividade de criação de mapa mentais foi realizada com as turmas do semestre 2020/2 das disciplinas de Fundamentos de Engenharia de Tráfego (FET) e Gestão de Sistemas Viários (GSV) de um curso de Engenharia de Transportes durante o ERE.

No ambiente virtual de aprendizagem de ambas as disciplinas em questão foram disponibilizados quatro vídeos explicativos acerca da construção de mapas mentais. $O$ primeiro explicava o objetivo da atividade a ser realizada, o segundo vídeo apresentava e o conceito por trás do mapa mental e os vídeos três e quatro exibiam as formas de criação de mapa mental utilizando diferentes softwares - GitMind e Microsoft Word, respectivamente. A

Figura 1 apresenta o texto e itens criados no ambiente virtual de aprendizagem da disciplina FET, o mesmo foi realizado para a disciplina GSV - com as devidas alterações de conteúdo a ser abordado.

Figura 1 - Explicação da atividade no ambiente virtual de aprendizagem.

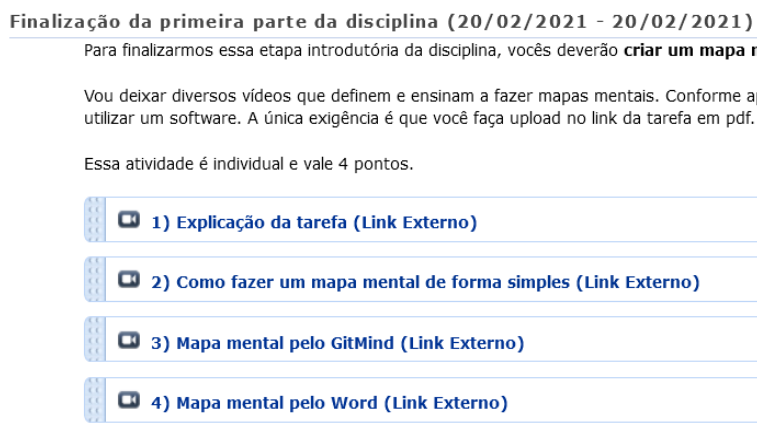

A atividade da disciplina FET consistia no resumo da primeira etapa da disciplina, destacando seus pontos chave. Tendo em vista a natureza teórica das primeiras aulas da disciplina, percebeu-se a necessidade de empregar um método que permitisse recordar e relacionar os conteúdos de aulas passadas. A Figura 2 apresenta um exemplo de mapa mental confeccionado por um aluno da disciplina.

A atividade de GSV se assemelhava à realizada com FET, com as devidas alterações de conteúdo. Nesta disciplina, o mapa mental foi empregado para realizar um resumo de uma palestra que aconteceu em aula, tendo como tema concessões viárias. A Figura 3 exibe um mapa mental confeccionado por um discente dessa disciplina. 
Figura 2 - Exemplo de mapa mental construído na disciplina de Fundamentos de Engenharia de Tráfego

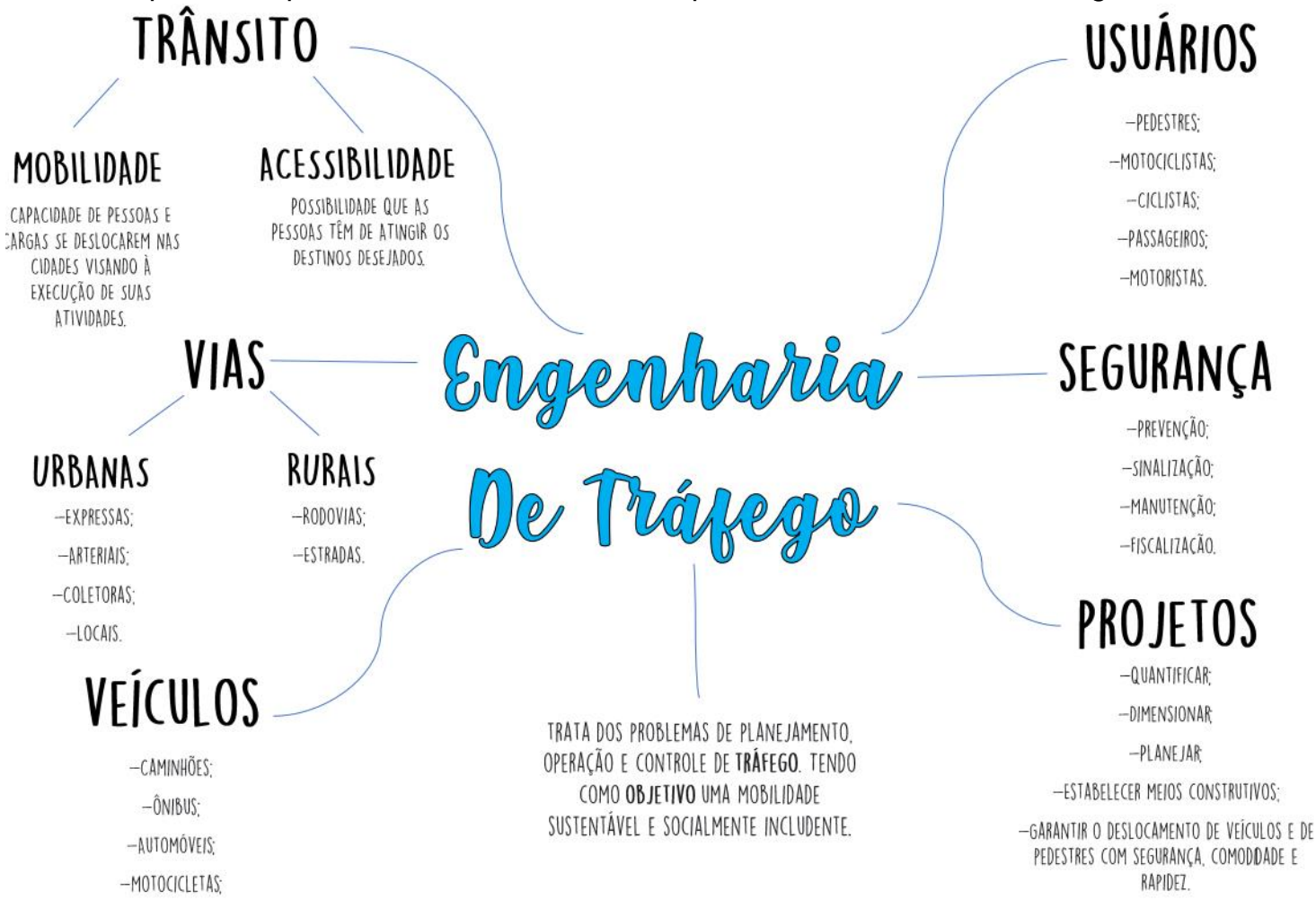

Figura 3 - Exemplo de mapa mental construído na disciplina de Gestão de Sistemas Viários

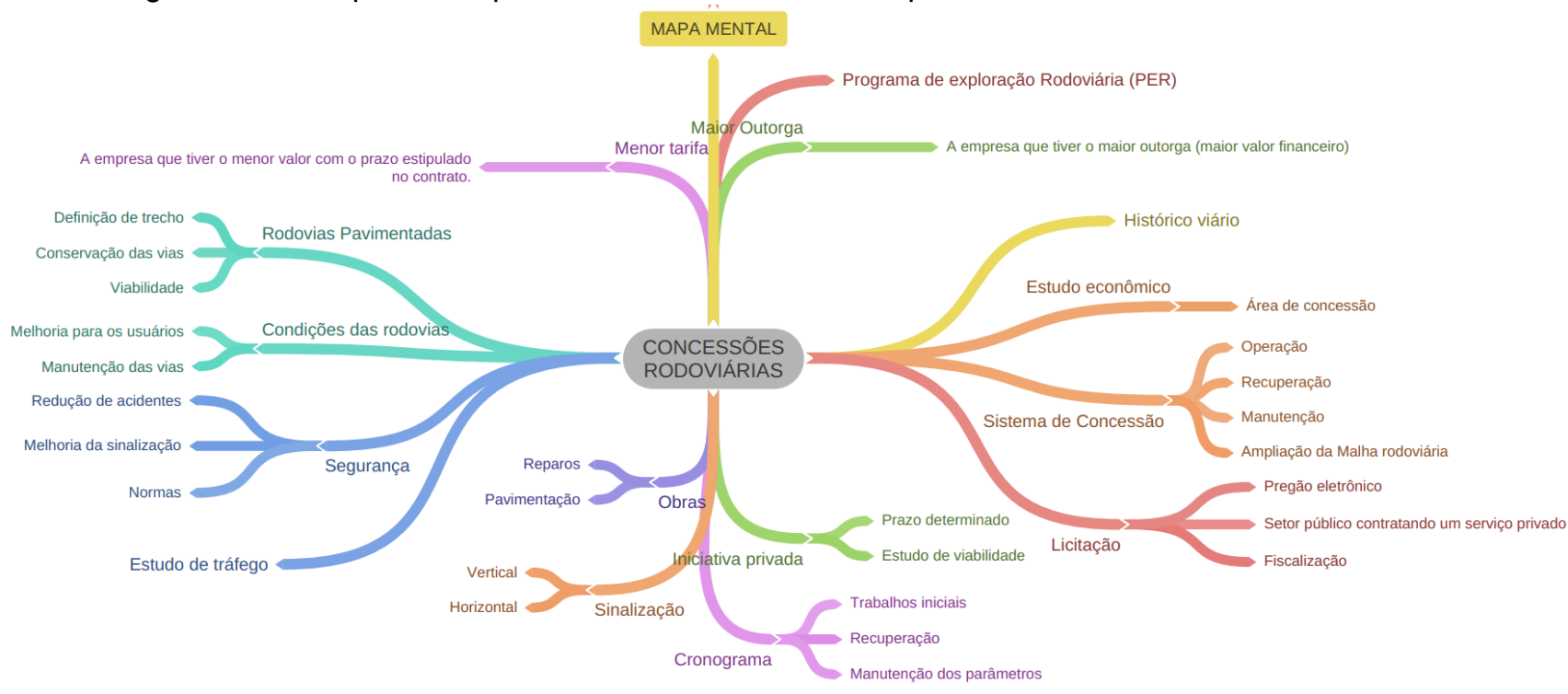

4 AVALIAÇÃO DA ATIVIDADE REALIZADA

As etapas seguidas pela presente pesquisa são apresentadas pela Figura 4. A primeira etapa, assim, consistiu na realização da atividade, apresentada no Tópico 3.

Figura 4 - Etapas realizadas

\begin{tabular}{c|c}
$\begin{array}{c}\text { Realização da } \\
\text { atividade }\end{array} \rightarrow \begin{array}{c}\text { Aplicação do } \\
\text { questionário de } \\
\text { avaliação }\end{array} \rightarrow\left[\begin{array}{c}\text { Análise das } \\
\text { respostas }\end{array} \rightarrow\right.$ Revisão e \\
aprimoramento da \\
atividade
\end{tabular}


A fim de avaliar o impacto da atividade realizada na assimilação do conteúdo e no processo de estudo, dias depois da entrega da atividade os discentes responderam um questionário online, construído no Google Forms, refletindo acerca da criação dos mapas mentais nas disciplinas, consistindo na segunda etapa da presente pesquisa (Figura 4).

O público-alvo da pesquisa de avaliação realizada foram os discentes matriculados nas disciplinas de Fundamentos de Engenharia de Tráfego e Gestão de Sistemas Viários. O questionário obteve 14 respostas, alcançando assim toda a população em estudo. É importante frisar que não existiam campos de identificação dos alunos - como: nome, email ou identificação acadêmica, garantindo assim a anonimidade dos respondentes. As perguntas exibidas aos discentes são apresentadas pelo Quadro 1.

Quadro 1 - Perguntas realizadas

\begin{tabular}{|c|c|c|}
\hline Seção & Pergunta & Campos de resposta \\
\hline \multirow[t]{2}{*}{ Seção 1} & $\begin{array}{l}\text { Você já conhecia (já tinha ouvido falar ou lido } \\
\text { sobre) o método de estudo mapa mental antes } \\
\text { do uso na disciplina? }\end{array}$ & Sim e não. \\
\hline & $\begin{array}{l}\text { Você já havia utilizado mapa mental antes de } \\
\text { empregá-lo na disciplina? }\end{array}$ & Sim e não. \\
\hline \multirow[t]{3}{*}{ Seção 2} & $\begin{array}{l}\text { O material de explicação sobre mapa mental } \\
\text { disponibilizado foi suficiente para compreender } \\
\text { como criá-lo. }\end{array}$ & $\begin{array}{l}\text { Concordo totalmente, } \\
\text { parcialmente, não concordo nem discordo, } \\
\text { discordo parcialmente e discordo } \\
\text { totalmente. }\end{array}$ \\
\hline & $\begin{array}{l}\text { A utilização desse método como forma de } \\
\text { estudo auxiliou no entendimento do conteúdo } \\
\text { ministrado. }\end{array}$ & $\begin{array}{l}\text { Concordo totalmente, } \\
\text { parcialmente, não concordo nem discordo, } \\
\text { discordo parcialmente e discordo } \\
\text { totalmente. }\end{array}$ \\
\hline & $\begin{array}{l}\text { Após a utilização dessa ferramenta na disciplina } \\
\text { pretendo aplicá-la em outros momentos de } \\
\text { estudo (seja para essa mesma matéria ou } \\
\text { outras). }\end{array}$ & $\begin{array}{l}\text { Concordo totalmente, } \\
\text { parcialmente, não concordo nem discordo, } \\
\text { discordo parcialmente e discordo } \\
\text { totalmente. }\end{array}$ \\
\hline \multirow[t]{3}{*}{ Seção 3} & $\begin{array}{l}\text { Você teve alguma dificuldade ao realizar a } \\
\text { atividade? }\end{array}$ & Sim e não. \\
\hline & $\begin{array}{l}\text { Se você teve alguma dificuldade ao realizar a } \\
\text { atividade, escreva ela aqui: }\end{array}$ & Campo de resposta aberto. \\
\hline & $\begin{array}{l}\text { Você tem alguma sugestão ou comentário a } \\
\text { respeito da atividade realizada? }\end{array}$ & Campo de resposta aberto. \\
\hline
\end{tabular}

Como pode ser observado no Quadro 1, o questionário era composto por três seções. Na primeira seção, buscava-se caracterizar o nível de conhecimento do estudante sobre mapas mentais antes do contato na disciplina - se os discentes já o conheciam e se já tinham o utilizado previamente. Na segunda parte do formulário, os discentes foram encorajados a avaliar a atividade proposta em sala, nas três perguntas que compunham essa seção foi utilizada a escala Likert para expressar concordância ou discordância com as afirmações apresentadas. Por fim, na última seção, os estudantes podiam expressar se apareceram dificuldades ao longo da atividade e propor melhorias para a mesma.

Retornando às etapas da pesquisa (Figura 4), a terceira parte desta consiste na avaliação das respostas obtidas, sendo utilizado o software Excel para as análises necessárias. Como último estágio, entende-se que os resultados deste trabalho também podem subsidiar melhorias para as atividades que ocorrerão nos próximos semestres. 


\section{RESULTADOS DA PESQUISA}

Por meio da pesquisa realizada, é possível afirmar que menos da metade dos discentes conheciam o mapa mental anteriormente ao uso nas disciplinas (Figura 5). Em contrapartida, $57 \%$ dos alunos não possuíam conhecimento da ferramenta empregada, denotando a necessidade de vídeos e conteúdos explicativos anteriores ao uso do método em sala de aula.

Figura 5 - Você já conhecia o mapa mental (já tinha ouvido falar ou lido sobre) antes do uso na disciplina?

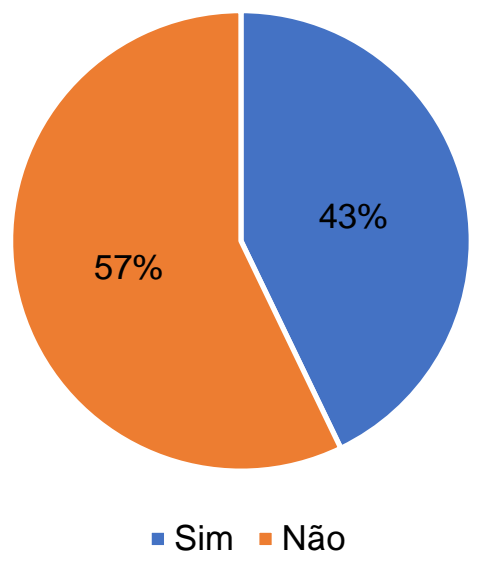

Quanto à utilização prévia do mapa mental, 29\% dos respondentes afirmaram já terem o empregado antes do uso na disciplina (Figura 6 ). Logo, mesmo que $43 \%$ dos alunos já conhecessem a ferramenta, poucos já haviam a utilizado - reforçando a necessidade dos vídeos apresentando o conceito e as formas de criar mapas mentais.

Figura 6 - Você já havia utilizado o mapa mental antes de empregá-lo na disciplina?

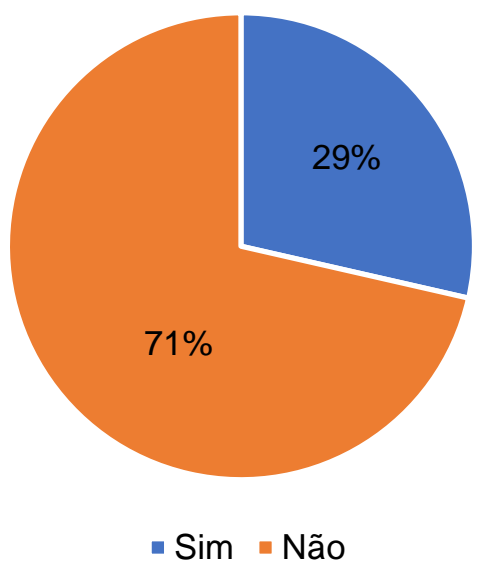

Ao serem indagados quanto à clareza do material disponibilizado como apoio à atividade proposta (Figura 7 ), $57 \%$ dos alunos entendem que o material foi suficiente para subsidiar a conclusão da tarefa. Por outro lado, $14 \%$ dos respondentes entendem que o material foi insuficiente, sinalizando que será preciso a adição ou reformulação de material ofertado. 
Figura 7 - O material de explicação sobre mapa mental disponibilizado foi suficiente para compreender como criá-lo.

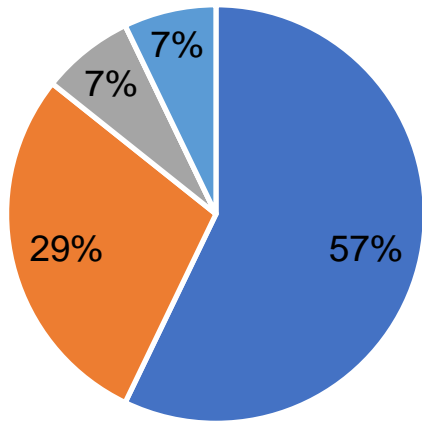

$$
\begin{aligned}
& \text { - Concordo totalmente } \quad \text { - Concordo parcialmente } \\
& \text { - Não concordo nem discordo } \text { - Discordo parcialmente } \\
& \text { - Discordo totalmente }
\end{aligned}
$$

Quanto à utilização do mapa mental como forma de facilitar o entendimento do conteúdo (Figura 8), 79\% dos discentes concordam totalmente que a sua utilização auxiliou no processo de aprendizagem. Ademais, nenhuma das respostas evidenciou discordância acerca da efetividade do mapa mental como ferramenta de assistência à absorção do conteúdo ministrado - corroborando com as afirmações de Hermann e Bovo (2006) e Buzan e Buzan (2009).

Figura 8 - A utilização desse método como forma de estudo auxiliou no entendimento do conteúdo ministrado.

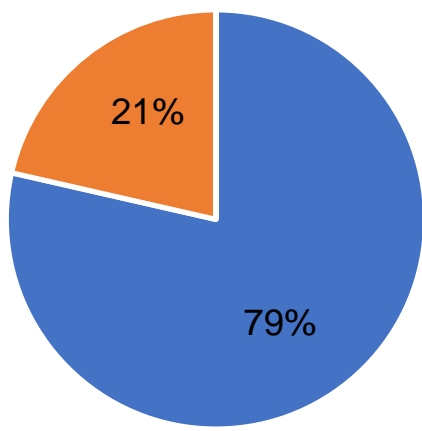

$$
\begin{aligned}
& \text { - Concordo totalmente } \quad \text { - Concordo parcialmente } \\
& \text { - Não concordo nem discordo } \text { - Discordo parcialmente } \\
& \text { - Discordo totalmente }
\end{aligned}
$$

Após o emprego do mapa mental na disciplina, cerca de $79 \%$ dos discentes demonstram a intenção de aplicar a ferramenta em outros momentos de estudo (Figura 9) - até mesmo em outras disciplinas. Por outro lado, $21 \%$ dos respondentes se mostraram indiferentes ao seu emprego em outras circunstâncias. Infere-se que em razão do mapa mental ser uma ferramenta que demanda um tempo maior para ser finalizada - ao contrário de somente uma leitura do texto, alguns discentes podem se demonstrar menos inclinados a empregá-lo sem haver um incentivo dentro das disciplinas. 
Figura 9 - Após a utilização dessa ferramenta na disciplina pretendo aplicá-la em outros momentos de estudo (seja para essa mesma matéria ou outras).

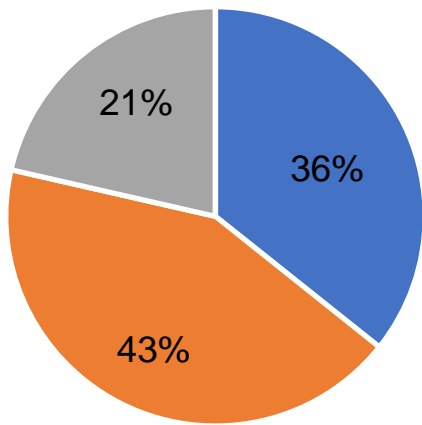

- Concordo totalmente $\quad$ - Concordo parcialmente

- Não concordo nem discordo - Discordo parcialmente

- Discordo totalmente

Movendo para a terceira, e última seção do questionário, os discentes foram questionados acerca de possíveis dificuldades que enfrentaram ao realizar a prática proposta (Figura 10), 69\% afirmaram que não encontraram problemas ao longo de sua elaboração. É importante recordar que cerca de $71 \%$ dos alunos nunca haviam criado um mapa mental até aquele momento, reforçando que o material disponibilizado foi de grande valia - não se descartando a necessidade do material de apoio da atividade, de forma a minimizar dificuldades encontradas por $31 \%$ dos alunos.

Figura 10 - Você teve alguma dificuldade ao realizar a atividade?

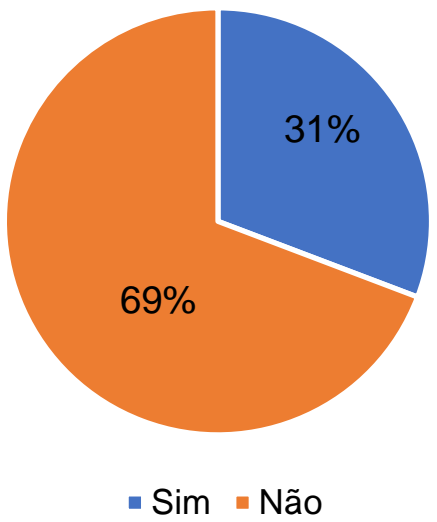

Como forma de completar a questão levantada pela questão da Figura 10, os discentes que encontraram dificuldades ao realizar a atividade foram encorajados a apresentar o problema enfrentado, as respostas dadas são apresentadas pelo Quadro 2. Não houve correção gramatical das respostas fornecidas.

Quadro 2 - Transcrição das respostas à pergunta: "se você teve alguma dificuldade ao realizar a atividade, escreva ela aqui:"

"É uma questão de prática e do método a se aplicar, quando analisado do seu perfil, qual melhor plataforma usar, definido seu método, tudo ocorre normalmente, a partir do uso constante vai se 
aprimorando o seu tempo, do mapa mental, com seu método já mentalizado. Tudo é questão de tempo

que no início inviabiliza o sistema, com o uso e aperfeiçoamento vai conseguindo uma melhor

performance."

"Só no início, após o momento inicial e com a prática transcorreu normalmente."

"Por ter sido uma das primeiras vezes que criei um mapa mental, ainda não estava muito familiarizado com o método, então tive um pouco de dificuldade para definir os pontos que seriam considerados."

Analisando os retornos obtidos no Quadro 2, percebe-se que a maior dificuldade enfrentada foi a falta de prática, o que é plausível considerando que mais da metade dos discentes nunca haviam o empregado. Por fim, a última questão do formulário buscava ouvir sugestões e comentários gerais acerca da atividade (Quadro 3).

Quadro 3 - Transcrição das respostas à pergunta: "você tem alguma sugestão ou comentário a respeito da atividade realizada?"

"Mapa mental para mim é algo que funcionou bastante quando era pré-vestibulando, entretanto na faculdade não tenho tido a mesma eficácia. De toda forma, acho interessante."

"É uma atividade de otimização, muito eficaz não apenas para o estudo, mas também para o trabalho como uma ferramenta de gestão de qualidade e visualização de um processo."

"Acredito que uma tarefa de mapa mental para a segunda parte da disciplina será muito interessante, tendo em vista que possui bastante conceitos e fórmulas."

"Foi muito satisfatório, e o método que mais gostei foi fazer no word, principalmente por não ter um padrão pré-estabelecido e várias fontes que pude baixar."

"Eu amei fazer o mapa mental e pretendo utiliza-lo em outras disciplinas."

"O incentivo ao uso do mapa mental é de grande importância para que possamos adquirir o hábito aplicálo mais vezes nos momentos de estudo, pois contribui muito para o aprendizado em qualquer disciplina.

De forma geral, as respostas para a questão do Quadro 3 são elogios à atividade realizada e ao método escolhido. Destaca-se o comentário da linha três, onde o discente sugere o emprego da atividade novamente para a segunda parte da disciplina de Fundamentos de Engenharia de Tráfego, em razão da quantidade de conceitos e fórmulas.

\section{CONSIDERAÇÕES FINAIS}

No contexto de universidades e escolas, a pandemia da COVID-19 trouxe diversos desafios para docentes e discentes. Um deles foi a necessidade de adaptação das disciplinas dadas de forma presencial para o virtual, buscando um nível de engajamento dos estudantes em um nível semelhante ao presencial. Dentro desse contexto, as metodologias ativas são aliadas do docente ao incentivarem a autonomia dos estudantes perante a construção do seu conhecimento.

Buscou-se empregar na atividade realizada os conceitos das metodologias ativas ao incentivar os discentes a estudarem os conteúdos ministrados por meio da construção de mapas mentais, de acordo com a disciplina em que este estava matriculado. Dessa forma, a atividade da disciplina FET consistia no resumo da primeira etapa da disciplina, ao passo que para GSV a ferramenta foi empregada para realizar uma síntese de uma palestra sobre concessões rodoviárias. 


\section{COOBENCE 28 a 30 de SETEMBRO}

Evento Online

"Formação em Engenharia:

Tecnologia, Inovação e Sustentabilidade"

Conforme as avaliações obtidas após à realização da atividade, pode-se entender que o mapa mental teve boa aceitação entre os alunos, com alguns deste cogitando utilizálo em outros momentos de estudo. Seguindo a sugestão dada por um aluno, é pretendido aplicar o mapa mental na segunda parte da disciplina FET.

Por fim, ainda que $79 \%$ dos discentes concordam que a utilização dos mapas mentais os auxiliou no processo de aprendizagem, se faz necessário revisar o material explicativo - uma vez que alguns estudantes entendem que este não foi suficiente para compreender como criá-lo, em decorrência de nunca terem utilizado a ferramenta anteriormente.

\section{REFERÊNCIAS}

BAEPLER, P. et al. A Guide to Teaching in the Active Learning Classroom: History, Research, and Practice. Richmond: Stylus Publishing, 2016. BLOKEHEAD, T. Mapeamento mental: guia passo a passo para iniciantes em criação de mapas mentais. Nova lorque: Babelcube Inc., 2016.

BUDD, J. W. Mind maps as classroom exercises. Journal of Economic Education, v. 35, n. 1, p. 35-46, 2004.

BUZAN, B.; BUZAN, T. The mind map book: unlock your creativity, boost your memory, change your life the mind map book. Londres: BBC Active, 2009.

CAMARGO, F.; DAROS, T. A sala de aula inovadora: estratégias pedagógicas para fomentar o aprendizado ativo. Porto Alegre: Penso, 2018.

CONSELHO NACIONAL DE SAÚDE. Recomendação n 027, de 22 de abril de 2020. Disponível em: <http://conselho.saude.gov.br/recomendacoes-cns/1132-recomendacao-n027-de-22-de-abril-de-2020>. Acesso em: 20 abr. 2021.

DHINDSA, H. S.; MAKARIMI-KASIM; ANDERSON, O. R. Constructivist-visual mind map teaching approach and the quality of students' cognitive structures. Journal of Science Education and Technology, v. 20, n. 2, p. 186-200, 2011.

DOLIVAL, R. G. et al. Mapa mental: uma abordagem possível para o ensino de matemática inclusiva. Horizontes - Revista de Educação, v. 5, n. 10, p. 182-194, 2017.

DOSEA, G. S. et al. Métodos ativos de aprendizagem no Ensino Online: a opinião de universitários durante a pandemia de Covid-19. Interfaces Científicas - Educação, v. 10, n. 1, p. 137-148, 2020.

FERLIN, E. P.; SHMEIL, M. A. H. Utilização das técnicas de aprendizagem ativa na educação em engenharia: estudo de caso dos Mapas Mentais. COBENGE. Anais...Evento On-line: 2020

GABRICH, F. DE A.; SOUZA, R. J. Revista de pesquisa e educação jurídica. Revista de Pesquisa e Educação Jurídica, v. 2016, p. 193-213, 2016.

HERMANN, W.; BOVO, V. Mapas Mentais - Enriquecendo Inteligências. Rio de Janeiro: Editora própria.

JUNIOR, V. B. DOS S.; MONTEIRO, J. C. DA S. Educação e COVID-19: as tecnologias digitais mediando a aprendizagem em tempos de pandemia. Revista Encantar Educação, Cultura e Sociedade, v. 2, p. 1-15, 2020.

LOPES, A. R. C.; RICHTER, D. A construção de mapas mentais e o ensino de Geografia: articulações entre o cotidiano e os conteúdos escolares. Revista Territorium Terram, v. 2, n. 3, p. 2-12, 2014.

MCGREW, R.; SAUL, J.; TEAGUE, C. Instructor's manual to accompany physics for scientists and engineers. 5. ed. Nova lorque: Serway \& Beichner, 2000.

MOREIRA, J. A. M.; HENRIQUES, S.; BARROS, D. Moving from emergency remote teaching to digital education in times of pandemic. Dialogia, n. 34, p. 351-364, 2020. 
OMS. OMS declara emergência de saúde pública de importância internacional por surto de novo coronavírus. Disponível em: $<$ https://www.paho.org/bra/index.php?option=com_content\&view=article\&id=6100:omsdeclara-emergencia-de-saude-publica-de-importancia-internacional-em-relacao-a-novocoronavirus\&ltemid=812>. Acesso em: 20 abr. $2021 \mathrm{a}$.

OMS. OMS afirma que COVID-19 é agora caracterizada como pandemia. Disponível em:

<https://www.paho.org/bra/index.php?option=com_content\&view=article\&id=6120:omsafirma-que-covid-19-e-agora-caracterizada-como-pandemia\&ltemid=812>. Acesso em: 20 abr. 2021b.

PRINCE, M. J.; FELDER, R. M. Inductive teaching and learning methods: definitions, comparisons, and research bases. Journal of Engineering Education, v. 95, n. 2, p. $123-$ 138, 2013.

VILLAS-BOAS, V. et al. Aprendizagem ativa na educação em engenharia. Aprendizagem ativa na educação em engenharia. Anais...Blumenau: Congresso Brasileiro de Educação em Engenharia - $\quad$ COBENGE, 2011Disponível em: <https://edisciplinas.usp.br/pluginfile.php/5659203/mod_resource/content/1/Capitulo SD3 Aprendizagem Ativa_VERSAO_FINAL.pdf>

\section{THE USE OF MENTAL MAPS AS A STUDY AND EVALUATION TOOL IN ENGINEERING}

Abstract: Active methodologies places the student at the center of the learning process, encouraging creativity and autonomy, among other skills. Mind maps can be understood as an active methodology as it encourages the student to build its knowledge, when organizing and mentally relating the presented content. This paper presents the use of mind maps as an activity of evaluation and presence in two different disciplines in an engineering course during the period of online learning. A research was carried out regarding the students' perception about the activity. $71 \%$ of the students had never used mind maps and only $31 \%$ of them reported difficulties to create it. It was also found, through the research, the positive impact of the activity in the assimilation of the content taught. In addition, $79 \%$ of the students intend to apply mind maps at other times of study. These facts demonstrate the viability and usefulness of this tool within a context of online classes, enabling active learning.

Keywords: Education. Active learning. Students' perception. Higher education. Online learning. 